\title{
Impaired training-induced angiogenesis process with loss of pericyte-endothelium interactions is associated with an abnormal capillary remodelling in the skeletal muscle of COPD patients
}

Léo Blervaque ${ }^{1 *}$ (D) Emilie Passerieux ${ }^{1}$, Pascal Pomiès ${ }^{1}$, Matthias Catteau ${ }^{1}$, Nelly Héraud ${ }^{2}$, Marine Blaquière ${ }^{3}$, François Bughin ${ }^{3}$, Bronia Ayoub ${ }^{3}$, Nicolas Molinari ${ }^{4}$, Jean-Paul Cristol ${ }^{3}$, Antonia Perez-Martin ${ }^{5}$, Jacques Mercier ${ }^{3}$, Maurice Hayot ${ }^{3}$ and Fares Gouzi ${ }^{3}$

\begin{abstract}
Chronic obstructive pulmonary disease (COPD) is associated with exercise intolerance and limits the functional gains in response to exercise training in patients compared to sedentary healthy subjects (SHS). The blunted skeletal muscle angiogenesis previously observed in COPD patients has been linked to these limited functional improvements, but its underlying mechanisms, as well as the potential role of oxidative stress, remain poorly understood. Therefore, we compared ultrastructural indexes of angiogenic process and capillary remodelling by transmission electron microscopy in 9 COPD patients and 7 SHS after 6 weeks of individualized moderate-intensity endurance training. We also assessed oxidative stress by plasma-free and esterified isoprostane $\left(F_{2}-\mid s o P\right)$ levels in both groups. We observed a capillary basement membrane thickening in COPD patients only $(p=0.008)$ and abnormal variations of endothelial nucleus density in response to exercise training in these patients when compared to SHS $(p=0.042)$. COPD patients had significantly fewer occurrences of pericyte/endothelium interdigitations, a morphologic marker of capillary maturation, than SHS $(p=0.014)$, and significantly higher levels of $F_{2}-\operatorname{IsoP}(p=0.048)$. Last, the changes in pericyte/endothelium interdigitations and $F_{2}-$ IsoP levels in response to exercise training were negatively correlated $(r=-0.62, p=0.025)$. This study is the first to show abnormal capillary remodelling and to reveal impairments during the whole process of angiogenesis (capillary creation and maturation) in COPD patients.
\end{abstract}

Trial registration: NCT01183039 \& NCT01183052, both registered 7 August 2010 (retrospectively registered).

Keywords: COPD, Capillaries, Angiogenesis, Skeletal muscle, Exercise training

\footnotetext{
* Correspondence: leo.blervaque@umontpellier.fr

'Physiologie \& médecine expérimentale du Cœur et des Muscles

(PhyMedExp), INSERM - CNRS - Montpellier University. CHU Arnaud De

Villeneuve, 371 avenue du Doyen Gaston Giraud, 34295 Montpellier cedex 5,

France

Full list of author information is available at the end of the article
}

(c) The Author(s). 2019 Open Access This article is distributed under the terms of the Creative Commons Attribution 4.0 International License (http://creativecommons.org/licenses/by/4.0/), which permits unrestricted use, distribution, and reproduction in any medium, provided you give appropriate credit to the original author(s) and the source, provide a link to the Creative Commons license, and indicate if changes were made. The Creative Commons Public Domain Dedication waiver (http://creativecommons.org/publicdomain/zero/1.0/) applies to the data made available in this article, unless otherwise stated. 


\section{Background}

Chronic obstructive pulmonary disease (COPD) is characterized by a persistent airflow limitation due to airway and/or alveolar abnormalities, and it is systematically associated with other concomitant chronic diseases [1]. Limb skeletal muscle dysfunction, for example, affects the morbi-mortality of these patients [2-4]. Yet, skeletal muscle capillarization, despite its key role in this dysfunction in COPD patients [5], is an under-considered explanation of this phenomenon. A previous study of our group nevertheless demonstrated a significantly lower increase in skeletal muscle capillarization in response to exercise training in COPD patients compared with sedentary healthy subjects (SHS) [6]. This blunted angiogenesis was linked to the limited functional gains from exercise training observed in the patients [6]. Thus, while impaired angiogenesis appears to be relevant to the muscle misadaptations to exercise training in COPD patients, it remains insufficiently understood.

Physiologically, the angiogenic process in response to exercise training is highly dynamic, resulting from a balance between pro- and anti-angiogenic factors. However, two main phases of angiogenesis have been described: an early phase of new capillary creation and a later phase of neo-capillary maturation [7]. The morphologic markers of capillary creation [abluminal endothelial (EC) sprouts or intraluminal EC folding] and maturation [pericyte/endothelium (Pc/EC) interdigitations] in skeletal muscle were initially described in studies using transmission electron microscopy (TEM) [8-11], which is the reference method for their identification $[12,13]$. Capillary remodelling in response to exercise training also appears to be linked to angiogenesis [12], and it too can be assessed by TEM through a morphometric analysis of the main capillary components (lumen, endothelium, basement membrane and pericytes) [8].

In chronic diseases like diabetes, both impaired angiogenesis [14] and pathological capillary remodelling [15] have been described in response to exercise training. Oxidative stress is a potential factor of these impairments, causing basement membrane protein accumulation [16] and pericyte apoptosis [17]. Moreover, oxidative stress promotes isoprostane formation, [18] which is a direct inhibitor of angiogenesis [19] and a promotor of pericyte loss [20]. In COPD patients, increased levels of plasma-free and esterified isoprostanes $\left(\mathrm{F}_{2}\right.$-IsoP) and muscle oxidative stress have been reported $[5,21,22]$. We thus hypothesized that the blunted angiogenesis in COPD patients in response to exercise training [6] would be associated with abnormal capillary remodelling, an impaired angiogenic process (i.e. capillary creation and maturation), and increased plasmatic oxidative stress levels.
Therefore, the aim of this study was to compare capillary remodelling and the morphologic markers of the angiogenic process in skeletal muscle after a 6-week exercise training programme in COPD patients and SHS. In addition, we sought to determine whether the changes in the capillary ultrastructure and the changes in plasmatic levels of $\mathrm{F}_{2}$-IsoP were correlated in both groups.

\section{Materials and methods Study design}

This study was conducted on skeletal muscle samples from subgroups of both COPD patients and SHS recruited in two previous studies (registration numbers for clinicaltrial.gov: NCT01183039 and NCT01183052). The subjects were recruited at PhyMedExp (INSERM-CNRSUM), Montpellier University Hospital, Montpellier, France, or the "La Solane" and "La Vallonie" Pulmonary Rehabilitation Centres in Osseja and Lodève, France. These studies were the subject of a previous publication [Gouzi et al., 2013] [6]. The present study used TEM to more closely investigate the underlying mechanisms of the blunted angiogenesis in response to exercise training found in the main study. The inclusion criteria are available in the previous study [6] and in clinicaltrials.gov/. Briefly, COPD patients were defined by dyspnoea, chronic cough or sputum production and/or a history of exposure to risk factors for the disease, and postbronchodilator forced expiratory volume in $1 \mathrm{~s} /$ forced ventilator capacity ratio $<70 \%$ [23]. The exclusion criteria were other respiratory diagnoses, decompensated comorbidity, exacerbation within the last 3 months, and previous participation in an exercise training programme. Study protocols followed the European guidelines for good clinical practice and the Declaration of Helsinki.

\section{Pulmonary function assessment}

Pulmonary function was assessed using whole-body plethysmography (Transmural Bodybox 2800; Sensomedics, Yorba Linda, CA, USA). $\mathrm{PaO}_{2}$ was measured in radial artery blood samples from seated COPD patients under room air condition, with a blood gas analyser (Roche OMNIS, Roche Diagnostics, Mannheim, Germany).

\section{Assessment of skeletal muscle function and exercise}

The 6-min walking test was conducted in accordance with the ATS statement [24]. COPD patients and SHS also performed an incremental cycloergometric test on a calibrated, electrically-braked cycloergometer (Ergoselect 200P, Ergolyne, Bitz, Germany) in accordance with the ATS/ACCP statement [25]. The mean $\mathrm{VO}_{2}$ value over 
the last $20 \mathrm{~s}$ of the test was used as symptom-limited oxygen uptake $\left(\dot{\mathrm{VO}}_{\mathrm{sl}}\right)$. The endurance time of the quadriceps $\left(\right.$ Tlim $\left._{\text {quad }}\right)$ was assessed at a frequency of 10 movements per minute at $30 \%$ of the maximal voluntary contraction, as previously described [6]. The level of physical activity was assessed using the Voorrips questionnaire (modified Baecke's questionnaire) [26].

\section{Exercise training programme}

The exercise training programme was conducted for 6 weeks with 3 or 4 sessions per week (20 sessions in total) and was supervised by an experienced clinician. The protocol was consistent with the ATS/ERS statements [27]. The sessions lasted $1.5 \mathrm{~h}$, with $45 \mathrm{~min}$ of endurance training (10 min of work at the intensity of the ventilatory threshold followed by $5 \mathrm{~min}$ of active recovery, repeated 3 times) completed by $30 \mathrm{~min}$ of strengthbuilding exercise (8-10 exercises, with sets of 10-15 repetitions). The exercise intensity for the endurance exercise was set individually to the heart rate at the ventilatory threshold [28] and continuously monitored during the session with a cardiofrequency meter. The cycloergometer load was increased over the course of the sessions to maintain the targeted heart rate. The load for the resistance exercise was set at $40 \%$ of the isotonic one-repetition maximum (1-RM) of each muscle (deltoid, biceps, triceps and quadriceps) at the first session and progressively increased, targeting 5-6 out of 10 on an exertion scale [29]. This exercise training programme was part of a multi-component and comprehensive pulmonary rehabilitation programme, and it was completed by six small group education sessions (1-1.5 $\mathrm{h}$ each) conducted by an experienced therapist specialized in improving health-related behaviours.

\section{Muscle biopsies}

Biopsies from the vastus lateralis muscle of the COPD patients and SHS were performed before and after exercise training, using the Bergström technique as previously described $[6,30]$. Each biopsy was separated into two samples: one part was immediately frozen in isopentane, precooled in liquid nitrogen, and stored at $-80^{\circ} \mathrm{C}$ for histochemical analysis of muscle capillarization $(\mathrm{C} / \mathrm{F}$ ratio and fibre type characterization; for more details, see Gouzi et al., 2013 [6]); and one part was fixated with a solution of $2.5 \%$ glutaraldehyde in PHEM buffer (1X, $\mathrm{pH}$ 7.4) and stored at $4{ }^{\circ} \mathrm{C}$ for TEM analysis of capillary ultrastructure. The TEM samples were recut into smaller samples (about $12 \mathrm{~mm}^{3}$ ) and immersed in a second fixative solution $(0.5 \%$ osmic acid $)$ for $2 \mathrm{~h}$ in the dark at room temperature. After dehydration (graded series of ethanol, 30-100\%), these blocks were embedded in EmBed 812 resin using an Automated Microwave
Tissue Processor for Electronic Microscopy (Leica EM AMW) and cut into transversal sections $70 \mathrm{~nm}$ thick (Leica-Reichert Ultracut E). These sections were stained with a solution of uranyl acetate and lead citrate and observed with a Tecnai F20 transmission electron microscope at $120 \mathrm{kV}$ (CoMET MRI facilities, INM France) to analyse the capillary ultrastructure.

\section{TEM image analysis}

Quantitative and semi-quantitative analysis of TEM images was performed using ImageJ software. The software was systematically scaled for each image. A mean $12.3 \pm$ 3.2 capillaries/subject for each time (pre- and posttraining) was analysed by three independent blinded operators. The reproducibility of the measurement of capillary morphometry between the three operators was assessed. The mean value of the Lin concordance coefficient [31] was $0.98 \pm 0.02$. The capillary remodelling was assessed using morphometric analysis of the principal capillary components, as previously described [32]. The area (A) and circumference (C) of the capillary structures (Lum, EC, BM, Nucl and Pc) were obtained with the free-hand surrounding tool, as previously described [32]. The thickness (T) of Lum, EC and BM and Lum and the relative volume (RV) of EC, BM and Pc were calculated using formulae proposed by Bigler et al. (2016) [32]: $\mathrm{Lum}_{\mathrm{T}}=2 * \mathrm{~A}_{\mathrm{Lum}} / \mathrm{C}_{\mathrm{Lum}} ; \mathrm{EC}_{\mathrm{T}}=2 *\left[\left(\mathrm{~A}_{\mathrm{EC}}-\mathrm{A}_{\mathrm{Lum}}\right.\right.$ $\left.\left.-\mathrm{A}_{\mathrm{Nucl}}\right) /\left(\mathrm{C}_{\mathrm{EC}}+\mathrm{C}_{\mathrm{Lum}}+\mathrm{C}_{\mathrm{Nucl}}\right)\right] ; \mathrm{BM}_{\mathrm{T}}=2^{*}\left[\left(\mathrm{~A}_{\mathrm{BM}}-\mathrm{A}_{\mathrm{EC}}-\right.\right.$ $\left.\left.A_{P C}\right) /\left(C_{B M}+C_{E C}+C_{P C}\right)\right] ; \quad \operatorname{Lum}_{R V}=A_{L u m} / A_{B M} ; \quad E C_{R V}=[($ $\left.\left.A_{E C}-A_{L u m}\right) / A_{B M}\right] ; B M_{R V}=\left[\left(A_{B M}-A_{E C}\right) / A_{B M}\right] ; P c_{R V}=$ $\mathrm{A}_{\mathrm{PC}} / \mathrm{A}_{\mathrm{BM}}$. Endothelial nucleus density (ECNuclD) was calculated in the same manner: $\mathrm{ECNuclD}=\left[\mathrm{ECNucl}_{\mathrm{A}} /\right.$ $\left.\left(\mathrm{A}_{\mathrm{EC}}-\mathrm{Al}_{\mathrm{um}}\right)\right]$. Morphologic markers of the angiogenic process were assessed according to previous studies [12, 32]. The pericyte coverage (PcCov), considered as the ratio of the lines crossing the $\mathrm{BM} / \mathrm{EC}$ interface and at least one pericyte to the total lines crossing the BM/EC interface, was obtained using grid-based analysis with test points equal to $0.56 \mu \mathrm{m}^{2}$. A semi-quantitative analysis was performed to identify the percentage of capillaries associated with $\mathrm{Pc} / \mathrm{EC}$ interdigitations, abluminal EC sprouts and intraluminal EC folding [9, 12, 32].

\section{Markers of oxidative stress}

The levels of plasma-free and esterified isoprostanes $\left(\mathrm{F}_{2}\right.$ IsoP) were assessed to obtain an index of oxidative stress, as previously reported by Kadiiska et al. [33] and Roberts and Milne (2009). Venous blood samples were collected before and after exercise training and centrifuged $\left(2500 \mathrm{rpm}, 4^{\circ} \mathrm{C}, 10 \mathrm{~min}\right)$ and plasma was stored at $-80^{\circ} \mathrm{C}$ until analysis. Free and esterified plasmatic $F_{2}$ IsoP levels were determined using gas chromatographynegative ion chemical ionization mass spectrometry, as previously described [22]. 


\section{Statistical analysis}

Baseline characteristics of the COPD and SHS groups were compared with t-tests or the Mann-Whitney U depending on the normality and homoscedasticity of the data. Normality was assessed with the KolmogorovSmirnov (K-S) test and homoscedasticity with the Brown and Forsythe test [34]. The data are presented as MEAN (SD) or MEDIAN $\left(\mathrm{Q}_{1}-\mathrm{Q}_{3}\right)$ according to the $\mathrm{K}-\mathrm{S}$ test result. Correlations are described using the Pearson coefficient. As the two groups (SHS and COPD) were evaluated twice (before and after exercise training), we analysed the data with a linear mixed-effect model, taking into account the repeated measures and using the subject effect as a random effect. For this model, the fixed effects were the Time and Group effects and the interaction between these factors (Group x Time). For variables for which a single parametric value was obtained for each capillary, we performed a multilevel linear mixed-effect model, clustering each capillary value according to its subject of origin to avoid the inflation of Type I error [35]. Linear mixed models were fit using the lme function from the nlme $\mathrm{R}$ package [36]. To further detail our results, we completed the analysis with Fisher's LSD post-hoc test when the Group $x$ Time interaction term was significant. The normality of the residual distribution was assessed by a Q-Q plot after each lme test [37]. Data were analysed with Statistica 7.1 (StatSoft, Inc.) and R 3.5.0 software (www.r-project.org). Data were plotted using GraphPad Prism 5 (GraphPad Software). A $p$-value $<0.05$ was considered significant.

\section{Results}

Baseline values of clinical, functional and histomorphologic parameters and changes in response to exercise training

Among 24 COPD patients and 23 SHS included in the main study [Gouzi et al., 2013] [6], we selected all patients for whom we had at least one muscle sample conditioned for TEM analysis, i.e. 9 COPD patients and 7 SHS. The baseline clinical characteristics of the COPD patients and SHS are presented in Table 1.

As shown in Table 2, exercise training induced significant improvement in 6-min walking distance (\%pred.) and in endurance time of the quadriceps $\left(\mathrm{Tlim}_{\text {quad }}\right)$ in both groups (Time effect: $p<0.001$ and $p=0.009$, respectively). As expected, these two functional parameters were significantly lower in COPD patients than in SHS, regardless of the training effect (Group effect: $p=0.006$ and $p=0.024$, respectively). A differential effect of exercise training on symptom-limited oxygen uptake $\left(\mathrm{V}_{2 \mathrm{sl}}\right)$ was found in COPD patients compared with SHS (Group $\mathrm{x}$ Time interaction: $p=0.020$ ) with a significant increase in the SHS group only (SHS: $13.8 \pm 10.4 \%, p=$
Table 1 Baseline clinical and functional characteristics of COPD patients and SHS

\begin{tabular}{llll}
\hline & COPD & Control & $p$-value \\
\hline $\mathrm{N}$ & 9 & 7 & \\
Sex ratio (male/female) & $8 / 1$ & $6 / 1$ & \\
Age (years) & $57.3(6.0)$ & $62.6(4.5)$ & $\mathrm{NS}$ \\
$\mathrm{FEV}_{1}$ (\% pred.) & $54.6(17.5)$ & $116.0(13.1)$ & $p<0.001$ \\
$\mathrm{FEV}_{1} / \mathrm{VC}$ & $43.6(9.6)$ & $76.2(4.4)$ & $p<0.001$ \\
$\mathrm{PaO}_{2}$ (mmHg) & $71.1(9.9)$ & & \\
$\mathrm{PA} \mathrm{level}$ & $7.3(3.2-8.3)$ & $4.1(1.7-4.9)$ & $\mathrm{NS}$ \$
\end{tabular}

Data are presented as mean (SD) or median (Q1-Q3). FEV 1 Forced expiratory volume in $1 \mathrm{~s}$, VC slow vital capacity, \% pred: \% predicted, $\mathrm{PaO} 2$ arterial oxygen tension, PA Physical activity. ${ }^{\S}$ Mann-Whitney U Test

0.003 vs COPD: $5.1 \pm 8.1 \%, p=0.28$ ). Regarding the histochemical data, COPD patients showed lower baseline values for the capillary-to-fibre $(\mathrm{C} / \mathrm{F})$ ratio compared with SHS ( $p=0.002$ and $p=0.024$, respectively; Table 2 ). In response to exercise training, we observed lower improvement in the $\mathrm{C} / \mathrm{F}$ ratio of COPD patients than SHS $(+15 \%$ versus $+30 \%$; Group $\mathrm{x}$ Time interaction: $p=$ $0.003)$, leading to persistent lower post-training values in COPD patients compared with SHS $(p<0.001)$. Similarly, COPD patients presented a reduction of type I fibre proportion in response to exercise training leading to lower post-training values compared to SHS (Group $\mathrm{x}$ Time interaction: $p=0.01$; Additional file 1: Figure. S1).

Angiogenesis-related capillary remodelling in response to exercise training.

Capillaries from the vastus lateralis muscle biopsies, obtained before and after exercise training in the 9 COPD patients and 7 SHS, were analysed by TEM. The analyses were performed on 392 capillary profiles, which were always composed of at least Lum, EC and BM. Neither total capillary area nor the number of analysed capillaries differed between groups or training times $(p>$ 0.05; data not shown). As shown in Table 3, the baseline values of lumen (Lum), endothelium (EC), basement membrane $(\mathrm{BM})$ and pericyte $(\mathrm{Pc})$ relative volume $(\mathrm{RV})$ and thickness $(\mathrm{T})$ did not differ between COPD patients and SHS.

Standard transmission electron micrographs of the skeletal muscle capillaries in COPD patients and SHS, before and after exercise training, are shown on Fig. 1a. Variations of relative volume and thickness of each capillary compartment in response to exercise training are presented in Fig. 1b. In response to exercise training, we observed a significant decrease in Lum $_{\mathrm{RV}}$ (COPD: $16.4 \pm 21.5 \%$; SHS: $-23.3 \pm 22.1 \%$; Fig. $1 \mathrm{~b}$ ) and Lum $_{\mathrm{T}}$ (COPD: $-7.1 \pm 36.8 \%$; SHS: $-17.2 \pm 22.4 \%$; Fig. $1 \mathrm{~b})$ in both groups (Time effect: $p<0.001$ and $p=0.002$, respectively). Conversely, a significant training-induced increase was found in both $\mathrm{EC}_{\mathrm{RV}}$ (COPD: + $17.0 \pm 24.1 \%$; 
Table 2 Functional and histomorphologic changes in response to exercise training in COPD patients and SHS

\begin{tabular}{|c|c|c|c|c|c|}
\hline & \multicolumn{2}{|l|}{ Pre-training } & \multicolumn{2}{|l|}{ Post-training } & \multirow[t]{2}{*}{$p$-value } \\
\hline & COPD & SHS & COPD & SHS & \\
\hline \multicolumn{6}{|l|}{ Functional parameters } \\
\hline$\dot{\mathrm{v}} \mathrm{O}_{2 \mathrm{~s}}(\%$ pred.) & $69.3(17.3) \neq$ & $113.7(12.7)$ & $72.44(17.2) \neq$ & $125.6(9.6))^{\# \# \#}$ & $\begin{array}{l}\mathrm{T}: p=0.004 \\
\mathrm{G}: p<0.001 \\
\text { GxT: } p=0.020\end{array}$ \\
\hline$\dot{\mathrm{V}} \mathrm{O}_{2 \mathrm{sl}}(\mathrm{ml} / \mathrm{min} / \mathrm{kg})$ & $19.8(4.7) \neq$ & $30.1(4.4)$ & $21.6(4.1) \neq$ & $33.1(7.9)^{\# \#}$ & $\begin{array}{l}\mathrm{T}: p=0.009 \\
\mathrm{G}: p<0.001 \\
\mathrm{GxT}: p=0.046\end{array}$ \\
\hline 6MWD (\%pred.) & $77.2(10.7)$ & $94.0(7.3)$ & $84.2(11.5)$ & $98.7(7.7)$ & $\begin{array}{l}\text { T: } p<0.001 \\
\text { G: } p=0.006 \\
\text { GXT: NS }\end{array}$ \\
\hline $6 \mathrm{MWD}(\mathrm{m})$ & $539.6(60.9)$ & $643.3(60.9)$ & $591.2(72.4)$ & $684.6(60.5)$ & $\begin{array}{l}\text { T: } p<0.001 \\
\text { G: } p=0.010 \\
\text { GxT: NS }\end{array}$ \\
\hline Tlim quad $(\mathrm{sec})$ & $299.6(123.4)$ & $588.6(382.2)$ & $388.6(201.2)_{f}$ & $830.3(467)$ & $\begin{array}{l}\text { T: } p=0.009 \\
\text { G: } p=0.024 \\
\text { GXT: NS }\end{array}$ \\
\hline \multicolumn{6}{|c|}{ Histomorphologic parameters } \\
\hline $\mathrm{C} / \mathrm{F}$ ratio & $1.29(0.3) *$ & $1.67(0.3)$ & $1.49(0.3)^{\# \# \neq} \neq$ & $2.18(0.4) \# \# \#$ & $\begin{array}{l}\text { T: } p<0.001 \\
\text { G: } p=0.004 \\
\text { GxT: } p=0.003\end{array}$ \\
\hline
\end{tabular}

Data are presented as mean (SD). $\dot{\mathrm{O}}_{2 \mathrm{~s}}$ : symptom-limited oxygen uptake, $6 M W D$ 6-min walking distance, Tlim quad: endurance time of quadriceps, $\mathrm{C} / \mathrm{F}$ ratio Capillary-to-fibre ratio. $\$: n=5, £: n=8$. Linear mixed-effect model, $G$ Group effect, $T$ Time effect, $G x T$ Group x Time interaction. Post-hoc analysis for GxT: different from SHS group at same time: ${ }^{*} p<0.05 ; \dagger p<0.01 ; \neq p<0.001$. Different from pre-training: ${ }^{\# \#} p<0.01 ;{ }^{\# \# \#<0.001}$

SHS: $+22.5 \pm 18.5 \%$; Fig. $1 \mathrm{~b})$ and $\mathrm{EC}_{\mathrm{T}}(\mathrm{COPD}:+27.1 \pm$ $24.9 \%$; SHS: $+24.7 \pm 31.0 \%$; Fig. $1 \mathrm{~b})$, regardless of the group (Time effect: $p<0.001$ for both). Similarly, we observed a significant increase in $\mathrm{Pc}_{\mathrm{RV}}$ in both the COPD and SHS groups (COPD: $+68.4 \pm 60.2 \%$; SHS: $+40.3 \pm$ 65.7\%; Time effect: $p<0.001$; Fig. 1b). Last, a significantly different response to exercise training was observed in COPD patients compared with SHS for $\mathrm{BM}_{\mathrm{RV}}$ (Group $\mathrm{x}$ Time interaction: $p=0.008$; Fig. 1b) and $\mathrm{BM}_{\mathrm{T}}$ (Group $\mathrm{x}$ Time interaction: $p=0.050$; Fig. 1b), with a significant increase only in the COPD group for both $\mathrm{BM}_{\mathrm{RV}}$ $(p=0.005 ;+14.1 \pm 22.6 \%$; SHS: $-2.2 \pm 17.3 \%$; Fig. $1 \mathrm{~b})$ and $\mathrm{BM}_{\mathrm{T}}(p=0.043 ;+9.7 \pm 13.8 \%$; SHS: $-0.8 \pm 20.2 \%$; Fig. 1b).

Changes in morphologic markers of the angiogenic process in response to exercise training.

Table 3 Baseline morphometric characteristics of capillary components in COPD patients and SHS

\begin{tabular}{llll}
\hline & COPD & SHS & p-value \\
\hline $\operatorname{Lum}_{T}(\mathrm{~nm})$ & $1227(634)$ & $1203(522)$ & 0.90 \\
$\mathrm{EC}_{\mathrm{T}}(\mathrm{nm})$ & $388(122)$ & $358(116)$ & 0.27 \\
$\mathrm{BM}_{\mathrm{T}}(\mathrm{nm})$ & $211(85)$ & $220(75)$ & 0.99 \\
$\operatorname{Lum}_{\mathrm{RV}}(\%)$ & $38.2(16.8)$ & $39.5(14)$ & 0.53 \\
$\mathrm{EC}_{\mathrm{RV}}(\%)$ & $29.6(9.1)$ & $27.8(8.3)$ & 0.30 \\
$\mathrm{BM}_{\mathrm{RV}}(\%)$ & $21.0(7)$ & $22.8(7.4)$ & 0.64 \\
$\mathrm{PC}_{\mathrm{RV}}(\%)$ & $5.7(4.8)$ & $5.9(4.4)$ & 0.82 \\
\hline
\end{tabular}

RV Relative volume, $T$ Thickness, Lum Lumen, EC, Endothelium, BM Basement membrane, Pc Pericyte. Data are presented as Mean (SD)
We quantified the ultrastructural morphologic markers of angiogenesis, which are presented on the transmission electron micrographs in Fig. 2a-c. As shown in Fig. 2d and e, the occurrence of intraluminal EC folding or abluminal EC sprouts did not increase significantly with exercise training $(p>0.05)$. COPD patients and SHS did not show different preor post-training values for these indexes either $(p>$ 0.05). Conversely, Pc/EC interdigitation occurrence was significantly lower in the COPD group than in SHS (Fig. 2f) (pre-training: $0.46 \pm 0.14 \%$ vs $0.56 \pm$ $0.22 \%$; post-training: $0.38 \pm 0.16 \%$ vs $0.67 \pm 0.21 \%$; Group effect: $p=0.014)$. Moreover, taking into account the baseline difference between COPD patients and SHS, we noted a tendency towards a differential effect of exercise training on this parameter between the two groups (Group $\mathrm{x}$ Time interaction: $p=0.062$ ). Similarly, we observed significantly different variations of endothelial nucleus density (ECNuclD) in the capillaries of COPD patients compared with SHS in response to exercise training (Group $\mathrm{x}$ Time interaction: $p=0.042$; Fig. $2 \mathrm{~g}$ ). ECNuclD tended to decrease in response to exercise training only in the COPD patients $(-7.3 \pm 67.1 \%, p=0.053$; Fig. 2 g), leading to a tendency towards lower post-training ECNuclD values in the patients compared with SHS $(p=0.080$; Fig. $2 \mathrm{~g})$. The pericyte coverage (PcCov) tended to increase significantly with exercise training in both groups (Time effect: $p=0.094$; Fig. 2h), with no difference between the groups (COPD: $+17.6 \pm$ $26.1 \%$; SHS: $+16.9 \pm 50.5 \%)$. 


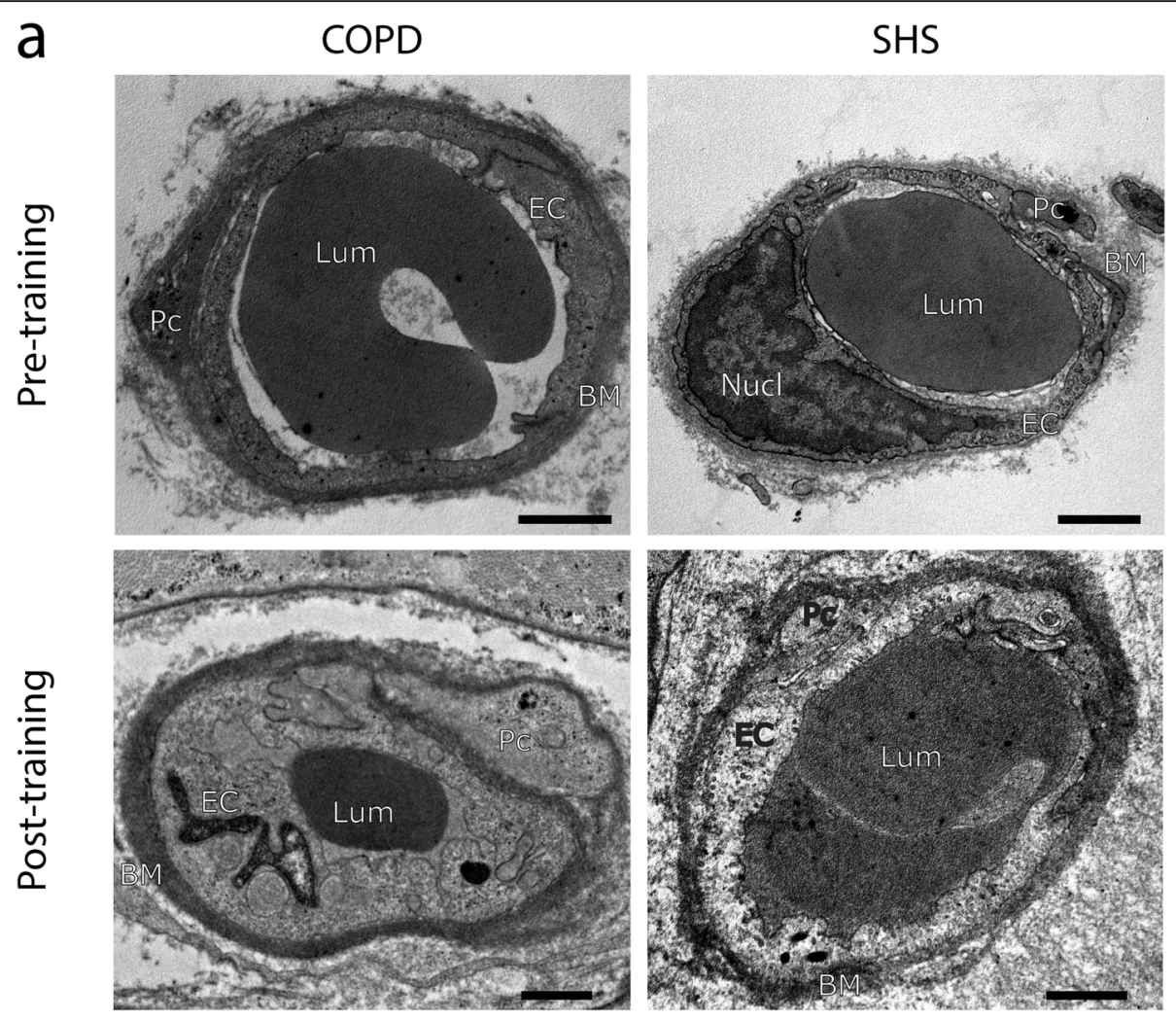

b

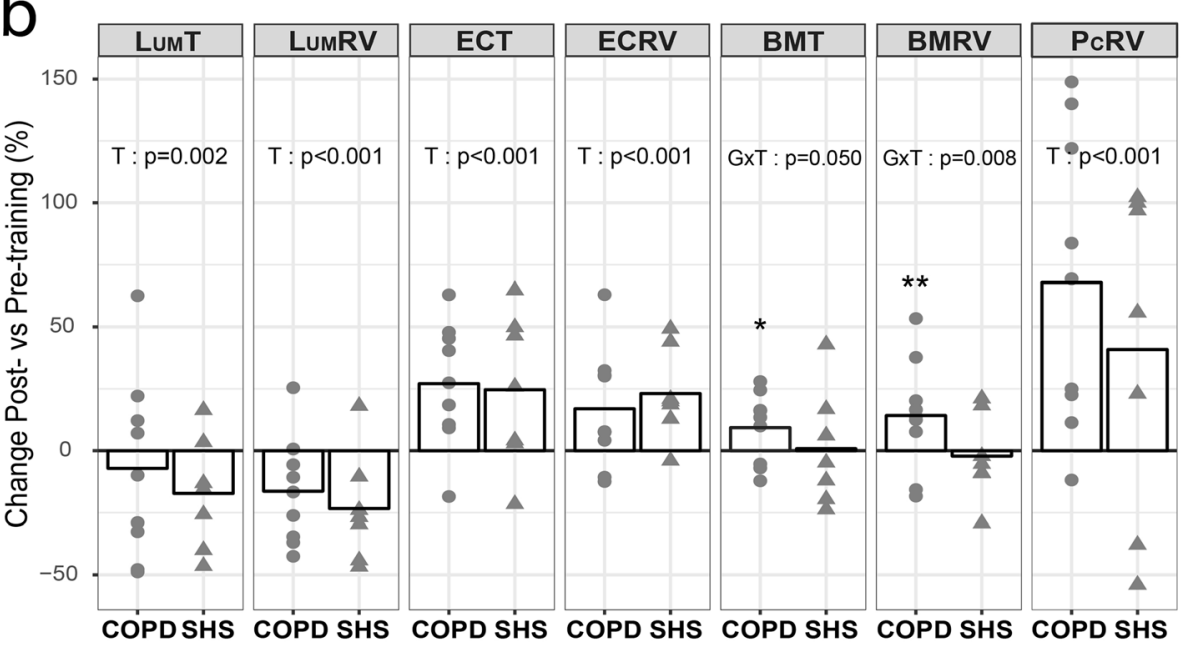

Fig. 1 Angiogenesis-related capillary remodelling in response to exercise training in skeletal muscle biopsies of COPD patients and SHS. a Transmission electron micrographs of capillaries from vastus lateralis biopsies of COPD patients and SHS. $\mathbf{b}$ Quantification of changes in relative volume and thickness of each capillary component following exercise training. RV: relative volume; T: thickness; Lum: lumen; EC: endothelium; BM: basement membrane; Pc: pericyte; Nucl: nucleus. Data are presented as means and individual values. Linear mixed-effect model: T: Time effect; GXT: Group x Time interaction. Post-hoc: Post-training different from Pre-training: ${ }^{*} p<0.05$; ${ }^{* *} p<0.01$. Scale bar: $1 \mu \mathrm{m}$

Correlations between the morphologic markers of the angiogenic process and the clinical, functional and histochemical parameters of COPD patients and SHS are presented in Fig. 3. After the 6-week exercise training programme, we found significant and positive correlations between the occurrence of $\mathrm{Pc} / \mathrm{EC}$ interdigitations and $\mathrm{FEV}_{1}$ (\%pred.; $\mathrm{r}=0.70, p=0.003$; Fig. 3a), $\dot{\mathrm{VO}}_{2 \mathrm{sl}}$ (\%pred.; $\mathrm{r}=0.57, p=0.034$; Fig. $3 \mathrm{~b}$ ).

\section{Training-induced changes in plasmatic $\mathrm{F}_{2}$-lso $\mathrm{P}$ levels}

As shown in Fig. 4a, plasmatic levels of $F_{2}$-IsoP decreased significantly with exercise training in both 

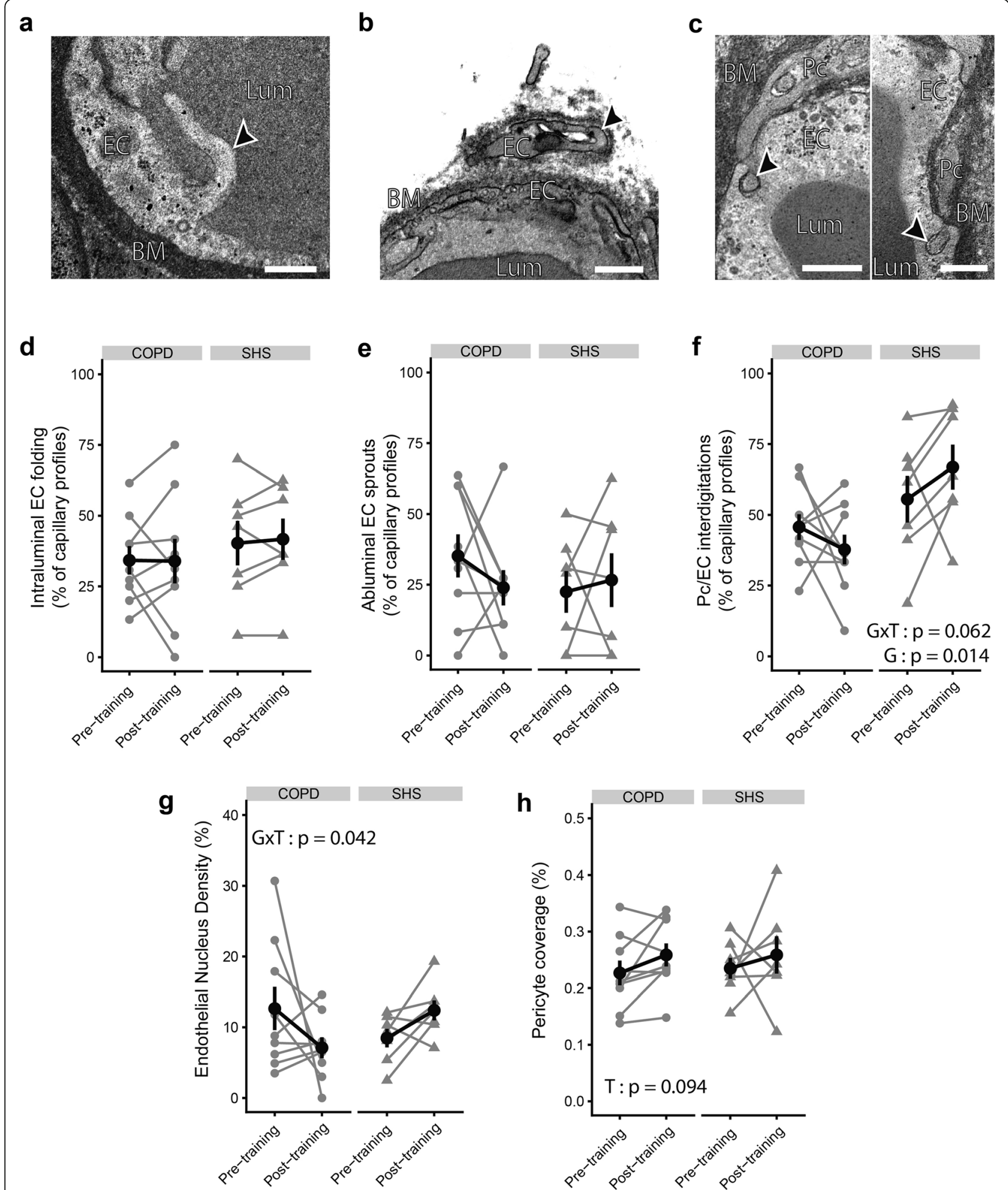

Fig. 2 Assessment of morphologic markers of the angiogenic process before and after exercise training in skeletal muscle biopsies of COPD patients and SHS. a-c Transmission electron micrographs focused on morphologic markers of angiogenesis, shown with black arrows: a intraluminal endothelial (EC) folding, $\mathbf{b}$ abluminal EC sprout, and $\mathbf{c}$ pericyte/endothelium (PC/EC) interdigitations. $d-f)$ Semi-quantitative analysis of the occurrence of intraluminal EC folding (d), abluminal EC sprouts (e), and PC/EC interdigitations (f) on transmission electron micrographs. $\mathbf{g}, \mathbf{h}$ Quantitative analysis of endothelial nucleus density $(\mathbf{g})$ and pericyte coverage $(\mathbf{h})$ on transmission electron micrographs. Lum: lumen; EC: endothelium; BM: basement membrane; PC: pericyte. Data are presented as mean \pm SE. Linear mixed-effect model: T: Time effect; G: Group effect; GxT: Group x Time interaction. Scale bar: 500 nm 
COPD patients and SHS $(-24.5 \pm 19.1 \%$ and $-31.1 \pm$ $17.2 \%$, respectively; Time effect: $p<0.001)$. However, regardless of exercise training, plasma $\mathrm{F}_{2}$-IsoP was significantly higher in COPD patients than in SHS (pretraining: $\quad 335.7 \pm 96.1$ vs $280.0 \pm 71.4$; post-training: $235.6 \pm 42.2$ vs $183.5 \pm 16.9$; Group effect: $p=0.048$; Fig. 4a). Moreover, as shown in Fig. 4b, we found a significant and negative correlation between the changes in $\mathrm{Pc} / \mathrm{EC}$ interdigitations and the changes in plasmatic levels of $\mathrm{F}_{2}$-IsoP in response to exercise training $(\mathrm{r}=-0.62, p=0.025)$.

\section{Discussion}

This study is the first to assess skeletal muscle capillary ultrastructure after exercise training-related angiogenesis in COPD patients. The main result is that the blunted training-induced angiogenesis previously found in COPD patients [6] is associated with abnormal capillary remodelling and morphologic features of an impaired angiogenic process.

Consistent with the previous study in this trial, COPD patients showed significant but blunted improvements in exercise capacity and muscle angiogenesis (Table 2) and an impaired adaptation of the muscle typology (Additional

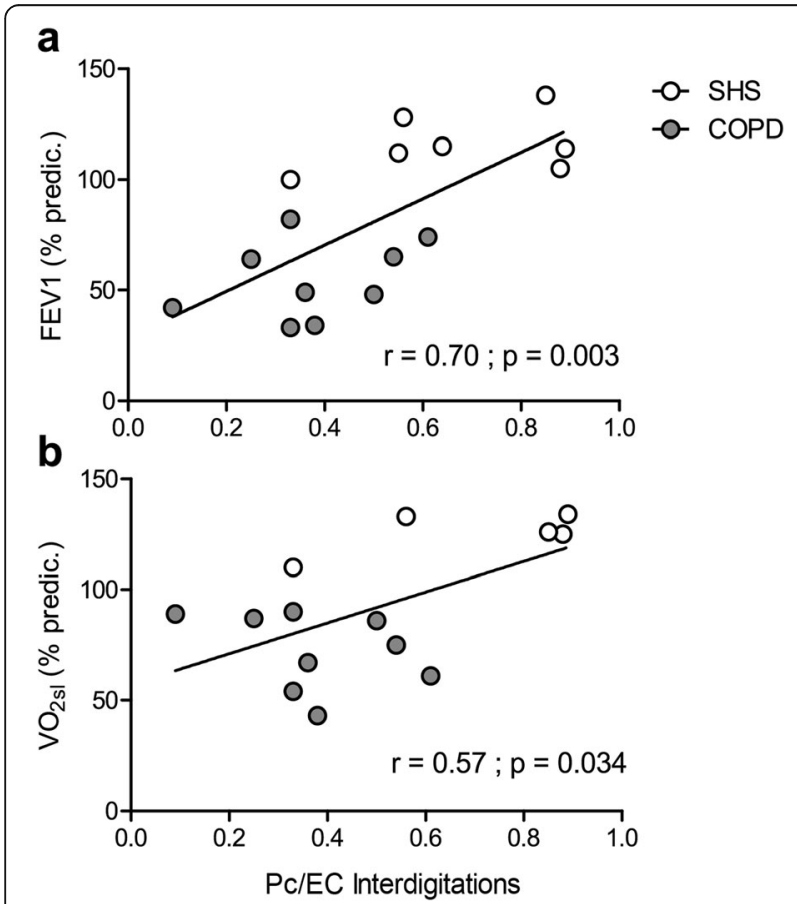

Fig. 3 Correlations between morphologic markers of the angiogenic process and clinical and functional parameters of COPD patients and SHS. Positive significant correlations between the proportion of capillary profiles associated with PC/EC interdigitations in posttraining vastus lateralis biopsies and $\mathbf{a}$ forced expiratory volume in 1 $\mathrm{s}\left(\mathrm{FEV} \mathrm{V}_{1}\right)$ (\% predic.), $\mathbf{b}$ post-training values of symptom-limited oxygen uptake $\left(\dot{\mathrm{V}}_{2 \mathrm{~s}}\right)$, in both COPD patients (grey circles) and SHS (white circles) file 1: Figure S1) in response to exercise training in comparison with sedentary healthy subjects. Together, these observations highlight an impairment of the oxidative metabolism of COPD patients and a misadaptation of this last to exercise training. However, the changes in fibre type under exercise training and the training-induced angiogenesis were poorly correlated (Additional file 1: Figure S1). Moreover, another study on COPD patients found differential angiogenic responses to exercise

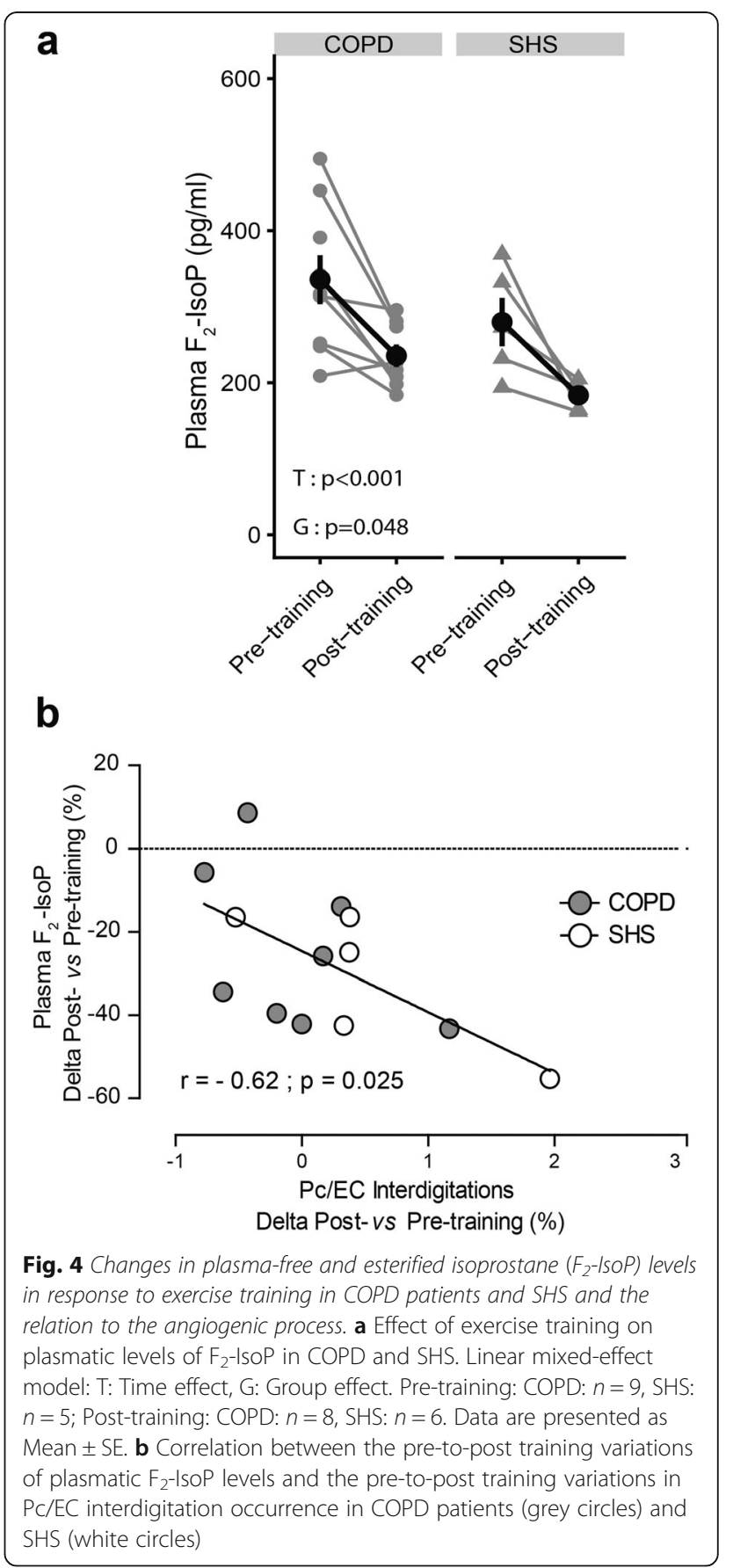


training between two groups of COPD patients, although the groups presented similar adaptations of skeletal muscle typology to the training [38]. Muscle typology alone was thus insufficient to explain the blunted angiogenesis found in these COPD patients, which led us to suspect that other cellular mechanisms might be involved. We therefore conducted this study to investigate capillary remodelling and the morphologic markers of the angiogenic process associated with the blunted training-induced angiogenesis found in these patients. The capillary remodelling and the morphologic markers of the angiogenic process were assessed blindly following cross-validated and previously published methods [12, 32]. The inter-observer reliability of the measurements of capillary remodelling was assessed with three observers and was "excellent" (according to Lin's concordance coefficient) [39].

Our study brings the first evidence of an exercise training effect on capillary ultrastructure in both COPD patients and healthy subjects between 50 and 70 years old and identified as strictly sedentary using a validated method. Both exercise training and ageing are known to alter the capillary ultrastructure in skeletal muscles $[12$, 32]. To isolate the impact of COPD on capillary ultrastructure and its response to exercise training, we selected COPD patients and SHS who did not differ in age or physical activity level for this study. In SHS, we observed a significant increase in both $\mathrm{EC}_{\mathrm{RV}}$ and $\mathrm{EC}_{\mathrm{T}}$ and no changes in $\mathrm{BM}_{\mathrm{RV}}$ and $\mathrm{BM}_{\mathrm{T}}$ in response to the training (Fig. 1b,c), as previous described in younger and more active healthy subjects [12, 40]. In contrast, we found a decrease in both Lum $\mathrm{RV}_{\mathrm{V}}$ and $\mathrm{Lum}_{\mathrm{T}}$ in these SHS following the training programme (Fig. 1b,c), and this decrease has been described as part of the angiogenic process in skeletal muscle $[9,10]$. Physiologically, angiogenesis occurs in two phases, an early phase of capillary creation (by sprouting and/or intussusception) in the first 5 weeks of exercise training and then a late phase of capillary maturation [7, 41]. Consistent with this timecourse, we observed later angiogenesis-related changes (increased PcCov and $\mathrm{PC}_{\mathrm{RV}}$ ) in SHS at 6 weeks of exercise training (Fig. $1 \mathrm{~b}$ and Fig. 2f,h) but not the early angiogenesis hallmarks (abluminal EC sprouts or intraluminal EC folding; Fig. 2d,e), in line with the findings of an earlier study in younger healthy subjects [12].

Conversely, the COPD patients presented an abnormal remodelling of capillaries in response to exercise training. While their adaptation of lumen ( $\operatorname{Lum}_{\mathrm{RV}}$ and $\operatorname{Lum}_{\mathrm{T}}$ ) and endothelium $\left(\mathrm{EC}_{\mathrm{RV}}\right.$ and $\left.\mathrm{EC}_{\mathrm{T}}\right)$ in response to training was physiological, they showed an unexpected increase in $\mathrm{BM}_{\mathrm{RV}}$ and $\mathrm{BM}_{\mathrm{T}}$ (Fig. 1b,c). The BM thickening after training was a non-physiological response, and this original result contrasts with what has been shown in other chronic diseases like hypertension, in which training induced BM thinning [40]. Exercise-induced oxidative stress [42], which is a hallmark of COPD, may be a mechanism in this modification, because oxidative stress disturbs the BM turnover in favour of an accumulation of the BM component [16]. Last, the loss of Pc/EC interdigitations (Fig. 2f) may also have contributed to the BM thickening. Indeed, these interdigitations act as a mechanical link between the endothelium and pericytes, helping the capillaries to resist the dramatic increase in haemodynamic forces during exercise $[43,44]$. Thus, the loss of the pericyte-endothelium link in COPD patients could be the cause of compensatory BM thickening.

In addition, our study showed an impaired angiogenic process in response to exercise training in the COPD patients. The skeletal muscle angiogenic process of COPD patients and SHS in response to exercise training was assessed through TEM analysis of the morphologic markers of specific capillary alterations [8-10, 12]. These markers inform about angiogenesis-related mechanisms and possible impairments [9, 12]. As described above, our measures were performed too late to assess the morphologic markers of the early phase of angiogenesis [7] (i.e. abluminal EC sprouts and intraluminal EC folding), and we thus found no changes in these markers in the COPD patients (Fig. 2d,e). However, it is possible to assess the final result of capillary proliferation by measuring the nucleus density in endothelial cells $[8,12]$. Here, we found a significantly different response to exercise training for the ECNuclD in the COPD patients compared with that of healthy subjects (Fig. 2g), suggesting impaired capillary proliferation during the angiogenic process. This finding is consistent with the blunted angiogenesis found at the histomorphologic level in these patients (Table 2). After 6 weeks of exercise training, we assessed the later phase of the angiogenic process, capillary maturation [7]. The Pc/EC interdigitations, as observed by TEM, are defined as the morphologic expression of capillary maturation [11], which increases during skeletal muscle stimulation [9]. In our study, we found a tendency towards a differential variation in the occurrence of the Pc/EC interdigitations in the COPD patients compared with SHS (Fig. 2f). Moreover, independently of exercise training, the patients presented a significantly lower occurrence of Pc/EC interdigitations. Surprisingly, the PcCov was not impaired in the COPD patients. However, while PcCov is described as a marker of capillary maturation, the maturation effect of pericyte is mainly driven by the exchange of multiple angiogenic factors. Among these, Ang1 plays a crucial role [45] and its exchange mostly occurs at the level of Pc/EC interdigitations [46]. Thus, while the PcCov in COPD patients was not impaired, the loss of Pc/EC interdigitations could lead to a dysfunctional pericyte coverage. However, both Ang1/Tie2 axis and pericyte function remains to be experimentally 
assessed in skeletal muscle capillaries of COPD patients. With these results, we bring the first evidence of impaired capillary maturation during exercise trainingrelated angiogenesis in COPD patients. Regardless of exercise training, the COPD patients in our study presented higher levels of plasmatic $\mathrm{F}_{2}$-IsoP, a marker of oxidative stress-related lipid peroxidation [18], than SHS (Fig. 4a). In addition, the changes in the occurrence of $\mathrm{Pc} / \mathrm{EC}$ interdigitations in response to the training were negatively correlated with the changes in the plasmatic level of $\mathrm{F}_{2}$-IsoP (Fig. 4b). In the literature, oxidative stress has been experimentally related to pericyte loss [17, 47]. Indeed, it can increase angiopoeitin-2 levels [48], which antagonize the interaction between endothelial cells and pericytes $[49,50]$. Moreover, partial suppression of $\mathrm{F}_{2}$-IsoP by antioxidant supplementation prevents pericyte loss [20]. Based on the literature and the $\mathrm{F}_{2}$-IsoP results of the present study, we hypothesize that oxidative stress can contribute to the impairment of capillary maturation found in COPD patients. Further experimental studies with oxidative stress intervention (pro- and anti-oxidant treatment in combination with training) in an animal model and COPD patients, associated with TEM analysis, are required to confirm this hypothesis.

The present study shows impairments in capillary remodelling and the angiogenic process in response to exercise training in COPD patients. As discussed in the previous paragraphs, our results constitute an original contribution to knowledge on the muscle cellular adaptations to cardiopulmonary rehabilitation. This study may be of interest to researchers working in the field of skeletal muscle dysfunction and angiogenesis in chronic respiratory diseases because it provides evidence that can guide their research questions and it specifically targets the angiogenesis mechanisms, i.e. the Pc/EC interactions. Our study constitutes a step forward in the search for complementary therapeutic interventions to restore physiological muscle adaptations to exercise training in COPD patients. While it was not the aim of our study, our results raise the question of their clinical relevance. Indeed, BM thickening increases the width of the capillary wall and thus the distance between erythrocytes and mitochondria. Because this distance is crucial in the process of oxygen diffusion and supply to the exercised muscle [51], this BM thickening might limit the improvements in muscle oxygen consumption and $\dot{\mathrm{VO}}_{2 \mathrm{sl}}$ in patients, as in peripheral artery disease patients [13]. Also, contractile pericytes [43] can directly regulate capillary blood flow [52]. Thus, the loss of the Pc/EC interdigitations in COPD patients might also impact the oxygen supply [53] and $\dot{\mathrm{V}}_{2 \mathrm{sl}}$. Consistently, we found a positive correlation between post-training Pc/EC interdigitation occurrence and $\dot{\mathrm{V}} \mathrm{O}_{2 \mathrm{sl}}$ (Fig. 3b). Last, given that capillary maturation prevents the regression of neocapillaries [54, 55], the impaired capillary maturation might constitute a mechanism for the blunted trainingrelated angiogenesis in COPD patients. Specifically designed studies with larger samples are required to generalize these results to the whole COPD population and to establish the clinical implications of the defective capillary remodelling and angiogenic process in these patients, as reported in our exploratory study.

\section{Conclusion}

Exercise training improves muscle function in COPD patients but to a lesser extent than in healthy subjects, especially regarding the increase in muscle capillarization (i.e. angiogenesis). Here, we provide the first evidence that this blunted angiogenesis is characterized by abnormal capillary remodelling and an impairment in both phases of the angiogenic process, i.e. capillary creation and maturation, in response to exercise training. The loss of pericyte-endothelium interaction appears to be a key factor for the capillary maturation. This study contributes to our understanding of the defective angiogenic process in COPD patients and constitutes a significant step towards isolating the blunted cellular mechanisms in endothelial cells and pericytes. Our observations suggest a hypothetic role for oxidative stress in the angiogenesis defect and open the way for further studies investigating this relationship in COPD patients.

\section{Supplementary information}

Supplementary information accompanies this paper at https://doi.org/10. 1186/s12931-019-1240-6.

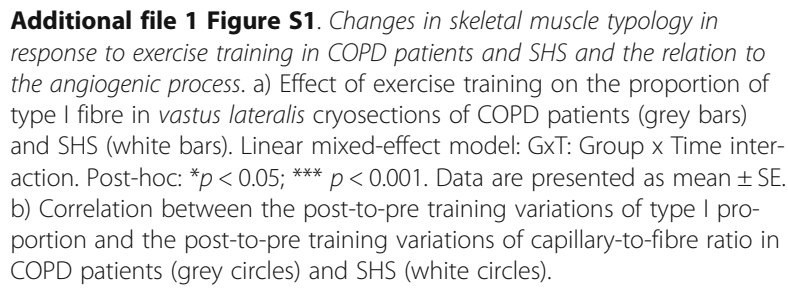
response to exercise training in COPD patients and SHS and the relation to the angiogenic process. a) Effect of exercise training on the proportion of type I fibre in vastus lateralis cryosections of COPD patients (grey bars) and SHS (white bars). Linear mixed-effect model: GXT: Group x Time interaction. Post-hoc: ${ }^{*} p<0.05 ;{ }^{* *} p<0.001$. Data are presented as mean \pm SE. b) Correlation between the post-to-pre training variations of type I proportion and the post-to-pre training variations of capillary-to-fibre ratio in COPD patients (grey circles) and SHS (white circles).

\section{Abbreviations \\ A: Area; BM: Basement Membrane; C: Circumference; C/F: Capillary-to-fibre; COPD: Chronic obstructive pulmonary disease; EC: Endothelial; \\ ECNucID: Endothelial nucleus density; F2-IsoP: Plasma-free and esterified isoprostane; FEV1: Forced expiratory volume in one second; Lum: Lumen; Pc: Pericyte; PcCov: Pericyte coverage; RV: Relative volume; SHS: Sedentary healthy subjects; T: Thickness; TEM: Transmission electron microscopy; Tlimquad: Endurance time of the quadriceps; $\dot{V}$ O2sl: Symptom-limited oxygen uptake}

\section{Acknowledgements}

The authors would like to thank Chantal Cazevieille from the COMET MRI facilities (INM, France) for her valuable help in tissue preparation for the transmission electron microscopy and micrograph acquisitions. We also would like to thank $C$. Stott for her critical reading of the manuscript. 


\section{Authors' contributions}

$L B, E P, M B, P P, F G$ and JPC performed the experiments. JM, PP, LB, FG, EP, $\mathrm{MH}$ and $\mathrm{MC}$ conceived and designed the experiments and discussed the data and the manuscript. JM, FG, PP and MH supervised the work. BA, EP, LB and $\mathrm{NM}$ collected and analysed the data. APM, FB and $\mathrm{NH}$ provided expertise and resources and discussed the data and the manuscript. LB wrote the manuscript. All authors reviewed the manuscript. All authors read and approved the final manuscript

\section{Funding}

This study was supported by joint grants from the Centre Hospitalier Régional Universitaire Montpellier, patient associations and the Association Pour l'Assistance et la Réhabilitation à domicile (APARD). FG was supported by a Conventions Industrielles de Formation par la Recherche (CIFRE) grant from the 5 Santé group, France, and the French Ministère Délégué à la Recherche et aux Nouvelles Technologies.

\section{Availability of data and materials}

The datasets used and/or analysed during the current study are available from the corresponding author on reasonable request.

\section{Ethics approval and consent to participate}

The two studies were approved by the institutional ethics committee of the Montpellier University Hospitals (2008-EESSS-V2 and 2009-04-BPCO-V2). All subjects had given informed written consent before starting the studies and agreed to the utilization of their muscle samples in future studies.

\section{Consent for publication}

Not applicable.

\section{Competing interests}

FG received financial support for congress participation from SOS Oxygène, LVL Médical, Eole Santé, APARD, Agir à Dom' and Bastide Médical. FB received financial support for congress participation from SOS Oxygène, LVL Médical, Orkyn, Eole Santé, APARD and Agir à Dom'. All other authors declare that they have no competing interest.

\section{Author details}

${ }^{1}$ Physiologie \& médecine expérimentale du Cœur et des Muscles (PhyMedExp), INSERM - CNRS - Montpellier University. CHU Arnaud De Villeneuve, 371 avenue du Doyen Gaston Giraud, 34295 Montpellier cedex 5, France. ${ }^{2}$ Les Cliniques du Souffle ${ }^{\oplus}$, Groupe 5 Santé, Lodève, France. ${ }^{3}$ PhyMedExp, INSERM - CNRS, Montpellier University, CHU Montpellier, Montpellier, France. ${ }^{4} \mathrm{IMAG}$, CNRS, Montpellier University, CHU Montpellier, Montpellier, France. ${ }^{5}$ Vascular Medicine Department and Laboratory, $\mathrm{CHU}$ Nîmes and EA2992 Research Unit, Montpellier University, Nimes, France.

\section{Received: 9 August 2019 Accepted: 13 November 2019}

\section{Published online: 05 December 2019}

\section{References}

1. Vanfleteren LEGW, Spruit MA, Groenen M, Gaffron S, van Empel VPM, Bruijnzeel PLB, et al. Clusters of Comorbidities Based on Validated Objective Measurements and Systemic Inflammation in Patients with Chronic Obstructive Pulmonary Disease. Am J Respir Crit Care Med. 2013;187(7): 728-35

2. Marquis $K$, Debigaré $R$, Lacasse $Y$, LeBlanc $P$, Jobin J, Carrier $G$, et al. Midthigh muscle cross-sectional area is a better predictor of mortality than body mass index in patients with chronic obstructive pulmonary disease. Am J Respir Crit Care Med. 2002;166(6):809-13.

3. Oga T, Nishimura K, Tsukino M, Sato S, Hajiro T. Analysis of the factors related to mortality in chronic obstructive pulmonary disease: role of exercise capacity and health status. Am J Respir Crit Care Med. 2003;167(4): 544-9.

4. Swallow EB, Reyes D, Hopkinson NS, Man WD-C, Porcher R, Cetti EJ, et al. Quadriceps strength predicts mortality in patients with moderate to severe chronic obstructive pulmonary disease. Thorax. 2007;62(2):115-20.

5. Maltais F, Decramer M, Casaburi R, Barreiro E, Burelle Y, Debigaré R, et al. An official American Thoracic Society/European Respiratory Society statement: update on limb muscle dysfunction in chronic obstructive pulmonary disease. Am J Respir Crit Care Med. 2014;189(9):e15-62.
6. Gouzi F, Préfaut C, Abdellaoui A, Roudier E, de Rigal P, Molinari N, et al. Blunted muscle angiogenic training-response in COPD patients versus sedentary controls. Eur Respir J avr. 2013;41(4):806-14.

7. Haas TL, Nwadozi E. Regulation of skeletal muscle capillary growth in exercise and disease. Appl Physiol Nutr Metab déc. 2015;40(12):1221-32.

8. Egginton S, Zhou A-L, Brown MD, Hudlická O. Unorthodox angiogenesis in skeletal muscle. Cardiovasc Res. 2001;49(3):634-46.

9. Egginton S, Hudlicka O, Brown MD, Graciotti L, Granata AL. In VivoPericyteendothelial cell interaction during angiogenesis in adult cardiac and skeletal muscle. Microvasc Res mars. 1996;51(2):213-28.

10. Zhou A-L, Egginton S, Brown MD, Hudlicka O. Capillary growth in overloaded, hypertrophic adult rat skeletal muscle: an ultrastructural study. Anat Rec Off Publ Am Assoc Anat. 1998:252(1):49-63.

11. Caruso RA, Fedele F, Finocchiaro G, Pizzi G, Nunnari M, Gitto G, et al. Ultrastructural descriptions of pericyte/endothelium peg-socket interdigitations in the microvasculature of human gastric carcinomas. Anticancer Res janv. 2009:29(1):449-53.

12. Baum O, Gübeli J, Frese S, Torchetti E, Malik C, Odriozola A, et al. Angiogenesis-related ultrastructural changes of capillaries in human skeletal muscle in response to endurance exercise. J Appl Physiol. 2015;119:11181126. jap.00594.2015.

13. Baum O, Bigler M. Pericapillary basement membrane thickening in human skeletal muscles. Am J Physiol Heart Circ Physiol. 2016;311(3): H654-66.

14. Wallberg-Henriksson H, Gunnarsson R, Henriksson J, Östman J, Wahren J. Influence of Physical Training on Formation of Muscle Capillaries in Type I Diabetes. Diabetes. 1984;33(9):851-7.

15. Raskin P, Pietri AO, Unger R, Shannon WA. The Effect of Diabetic Control on the Width of Skeletal-Muscle Capillary Basement Membrane in Patients with Type I Diabetes Mellitus. N Engl J Med. 1983:309(25):1546-50.

16. Mason RM, Wahab NA. Extracellular Matrix Metabolism in Diabetic Nephropathy. J Am Soc Nephrol. 2003;14(5):1358-73.

17. Hayden MR, Yang Y, Habibi J, Bagree SV, Sowers JR. Pericytopathy: oxidative stress and impaired cellular longevity in the pancreas and skeletal muscle in metabolic syndrome and type 2 diabetes. Oxidative Med Cell Longev. 2010; 3(5):290-303.

18. Roberts LJ, Milne GL. Isoprostanes. J Lipid Res avr. 2009;50(Suppl):S219-23.

19. Benndorf RA, Schwedhelm E, Gnann A, Taheri R, Kom G, Didié M, et al. Isoprostanes inhibit vascular endothelial growth factor-induced endothelial cell migration, tube formation, and cardiac vessel sprouting in vitro, as well as angiogenesis in vivo via activation of the thromboxane $A(2)$ receptor: a potential link between oxidative stress and impaired angiogenesis. Circ Res. 2008;103(9):1037-46.

20. Tsai GY, Cui JZ, Syed H, Xia Z, Ozerdem U, McNeill JH, et al. Effect of Nacetylcysteine on the early expression of inflammatory markers in the retina and plasma of diabetic rats. Clin Experiment Ophthalmol mars. 2009;37(2): 223-31.

21. Couillard A, Prefaut C. From muscle disuse to myopathy in COPD: potential contribution of oxidative stress. Eur Respir J oct. 2005:26(4):703-19.

22. Delample D, Durand F, Severac A, Belghith M, Mas E, Michel F, et al. Implication of xanthine oxidase in muscle oxidative stress in COPD patients. Free Radic Res janv. 2008;42(9):807-14.

23. Vogelmeier CF, Criner GJ, Martinez FJ, Anzueto A, Barnes PJ, Bourbeau J, et al. Global strategy for the diagnosis, management, and prevention of chronic obstructive lung disease 2017 report. GOLD Executive Summary Am J Respir Crit Care Med mars. 2017;195(5):557-82.

24. Statement ATS. ATS statement: guidelines for the six-minute walk test. Am J Respir Crit Care Med. 2002;166(1):111-7.

25. ATS/ACCP Statement. ATS/ACCP Statement on Cardiopulmonary Exercise Testing. Am J Respir Crit Care Med. 2003;167(2):211-77.

26. Voorrips LE, Ravelli AC, Dongelmans PC, Deurenberg P, Van Staveren WA. A physical activity questionnaire for the elderly. Med Sci Sports Exerc août. 1991;23(8):974-9.

27. Spruit MA, Singh SJ, Garvey C, ZuWallack R, Nici L, Rochester C, et al. An official American Thoracic Society/European Respiratory Society statement: key concepts and advances in pulmonary rehabilitation. Am J Respir Crit Care Med. 2013;188(8):e13-64.

28. Vallet G, Ahmaïdi S, Serres I, Fabre C, Bourgouin D, Desplan J, et al. Comparison of two training programmes in chronic airway limitation patients: standardized \&lt; \&gt;versus\&lt;/\&gt; individualized protocols. Eur Respir J. 1997;10(1):114-22. 
29. Nelson ME, Rejeski WJ, Blair SN, Duncan PW, Judge JO, King AC, et al. Physical activity and public health in older adults: recommendation from the American College of Sports Medicine and the American Heart Association. Med Sci Sports Exerc août. 2007:39(8):1435-45.

30. Hayot M, Michaud A, Koechlin C, Caron M-A, LeBlanc P, Préfaut C, et al. Skeletal muscle microbiopsy: a validation study of a minimally invasive technique. Eur Respir J. 2005;25(3):431-40.

31. Lawrence I, Lin K. A concordance correlation coefficient to evaluate reproducibility. Biometrics. 1989;45:255-68.

32. Bigler M, Koutsantonis D, Odriozola A, Halm S, Tschanz SA, Zakrzewicz A et al. Morphometry of skeletal muscle capillaries: the relationship between capillary ultrastructure and ageing in humans. Acta Physiol oct. 2016;218(2): 98-111.

33. Kadiiska MB, Gladen BC, Baird DD, Germolec D, Graham LB, Parker CE, et al. Biomarkers of oxidative stress study II: are oxidation products of lipids, proteins, and DNA markers of CCl4 poisoning? Free Radic Biol Med mars. 2005;38(6):698-710.

34. Brown MB, Forsythe AB. Robust tests for the equality of variances. J Am Stat Assoc juin. 1974;69(346):364-7.

35. Aarts $\mathrm{E}$, Verhage $\mathrm{M}$, Veenvliet JV, Dolan $\mathrm{CV}$, van der Sluis S. A solution to dependency: using multilevel analysis to accommodate nested data. Nat Neurosci avr. 2014;17(4):491-6.

36. Pinheiro J, Bates D, DebRoy S, Sarkar D. R Core Team (2014) nlme: linear and nonlinear mixed effects models. R package version 3; 2014. p. 1-117. Available H TtpCRAN R-Proj Orgpackage NIme

37. Faraway JJ. Extending the linear model with R: generalized linear, mixed effects and nonparametric regression models, vol. 124; 2016. CRC press

38. Costes F, Gosker H, Feasson L, Desgeorges M, Kelders M, Castells J, et al. Impaired exercise training-induced muscle fiber hypertrophy and Akt/mTOR pathway activation in hypoxemic patients with COPD. J Appl Physiol. 2015; 118(8):1040-9.

39. Partik BL, Stadler A, Schamp S, Koller A, Voracek M, Heinz G, et al. 3D versus 2D ultrasound: accuracy of volume measurement in human cadaver kidneys. Investig Radiol. 2002;37(9):489-95.

40. Gliemann L, Buess R, Nyberg M, Hoppeler H, Odriozola A, Thaning P, et al. Capillary growth, ultrastructure remodelling and exercise training in skeletal muscle of essential hypertensive patients. Acta Physiol juin. 2015;214(2):210-20.

41. Jain RK. Molecular regulation of vessel maturation. Nat Med juin. 2003;9(6): 685-93.

42. Couillard A, Maltais F, Saey D, Debigaré R, Michaud A, Koechlin C, et al. Exercise-induced Quadriceps Oxidative Stress and Peripheral Muscle Dysfunction in Patients with Chronic Obstructive Pulmonary Disease. Am J Respir Crit Care Med. 2003;167(12):1664-9.

43. Tilton RG, Kilo C, Williamson JR. Pericyte-endothelial relationships in cardiac and skeletal muscle capillaries. Microvasc Res. 1979;18(3):325-35.

44. Andersen P, Saltin B. Maximal perfusion of skeletal muscle in man. J Physiol sept. 1985;366:233-49.

45. Suri C, McClain J, Thurston G, McDonald DM, Zhou H, Oldmixon EH, et al. Increased Vascularization in Mice Overexpressing Angiopoietin-1. Science. 1998;282(5388):468-71.

46. Wakui S, Yokoo K, Muto T, Suzuki Y, Takahashi H, Furusato M, et al. Localization of Ang-1,-2, Tie-2, and VEGF expression at endothelial-pericyte interdigitation in rat angiogenesis. Lab Investig. 2006;86(11):1172.

47. Cacicedo JM, Benjachareowong S, Chou E, Ruderman NB, Ido Y. PalmitateInduced Apoptosis in Cultured Bovine Retinal Pericytes: Roles of NAD(P)H Oxidase, Oxidant Stress, and Ceramide. Diabetes. 2005;54(6):1838-45.

48. Mofarrahi M, Sigala I, Vassilokopoulos T, Harel S, Guo Y, Debigare R, et al. Angiogenesis-related factors in skeletal muscles of COPD patients: roles of angiopoietin-2. J Appl Physiol. 2013;114(9):1309-18.

49. Armulik A. Endothelial/Pericyte Interactions. Circ Res. 2005;97(6):512-23.

50. Zeng H, He X, Tuo Q, Liao D, Zhang G, Chen J. LPS causes pericyte loss and microvascular dysfunction via disruption of Sirt3/angiopoietins/Tie-2 and HIF-2a/Notch3 pathways. Sci Rep. [cité 12 déc 2018]; 2016;6:20931. Disponible sur: https://www.ncbi.nlm.nih.gov/pmc/articles/PMC4751495/.

51. Weibel ER. The Structural Conditions for Oxygen Supply to Muscle Cells: The Krogh Cylinder Model. J Exp Biol. 2013;216(22):4135-7.

52. Hall CN, Reynell C, Gesslein B, Hamilton NB, Mishra A, Sutherland BA, et al. Capillary pericytes regulate cerebral blood flow in health and disease. Nature avr. 2014;508(7494):55-60.
53. Kisler K, Nelson AR, Rege SV, Ramanathan A, Wang Y, Ahuja A, et al. Pericyte degeneration leads to neurovascular uncoupling and limits oxygen supply to brain. Nat Neurosci mars. 2017;20(3):406-16.

54. Gianni-Barrera R, Burger M, Wolff T, Heberer M, Schaefer DJ, Gürke L, et al. Long-term safety and stability of angiogenesis induced by balanced singlevector co-expression of PDGF-BB and VEGF164 in skeletal muscle. Sci Rep. 2016; [cité 12 déc 2018];6. Disponible sur: https://www.ncbi.nlm.nih.gov/ pmc/articles/PMC4756385/.

55. Erber R, Thurnher A, Katsen AD, Groth G, Kerger H, Hammes H-P, et al. Combined inhibition of VEGF and PDGF signaling enforces tumor vessel regression by interfering with pericyte-mediated endothelial cell survival mechanisms. FASEB J. 2004;18(2):338-40.

\section{Publisher's Note}

Springer Nature remains neutral with regard to jurisdictional claims in published maps and institutional affiliations.
Ready to submit your research? Choose BMC and benefit from:

- fast, convenient online submission

- thorough peer review by experienced researchers in your field

- rapid publication on acceptance

- support for research data, including large and complex data types

- gold Open Access which fosters wider collaboration and increased citations

- maximum visibility for your research: over $100 \mathrm{M}$ website views per year

At $\mathrm{BMC}$, research is always in progress.

Learn more biomedcentral.com/submissions 